\title{
The Impact of Moral Awareness on the Entrepreneurial Orientation- Performance Relationship in New Technology Based Firms
}

\author{
Héctor Montiel-Campos', Francesc Solé-Parellada ${ }^{2}$, Luis A.Aguilar-Valenzuela ${ }^{3}$, \\ Jasmina Berbegal-Mirabent ${ }^{4}$, Jorge A. Duran-Encalada ${ }^{5}$
}

\begin{abstract}
Prior studies have suggested the predominant role of the founder-manager's moral awareness in the emergence and persistence of a strong entrepreneurial culture likely to shape the firm's collective behavior. Although the strategic importance of founder-manager's moral awareness on a general level is undisputed, one major shortcoming of prior studies has been to evaluate his influence in the firm. The purpose of this exploratory study was to examine the effect of technology founder-manager's moral awareness on the entrepreneurial orientation-performance relationship in New Technology Based Firms. Not only do the results suggest that performance is positively influenced by its entrepreneurial orientation, but the findings also indicate that technology founder-manager's moral awareness moderates the relationship. The entrepreneurial orientation-performance link is stronger for low levels of moral awareness. The study's implications and future research directions are discussed.
\end{abstract}

Keywords: New technology based firms; moral awareness; entrepreneurial orientation; firm performance; technology founder-manager.

\footnotetext{
' Family Business Research Center. Universidad de las Américas Puebla. Ex hacienda Sta. Catarina Mártir, Cholula, Puebla 728I0, México. Tel. +52 (222) 22924 79. E-mail: hector.montiel@udlap.mx

2 Department of Management. Universitat Politècnica de Catalunya.Av. Diagonal 649, Building 7, Campus Sud Barcelona 08028, Spain. Tel. +34 (93) 41376 23. E-mail: francesc.sole@upc.edu

${ }^{3}$ Centro de Investigación en Alimentación y Desarrollo,A.C., Carr. a la Victoria, Km. 0.6, Hermosillo, Sonora 83304, México.

Tel. +52 (662) 21376 32. E-mail; aaguilar@ciad.mx

${ }^{4}$ Department of Management. Universitat Politècnica de Catalunya. C/ Jordi Girona, I-3. Building C5 Office 0I2 Barcelona 08034, Spain. Tel. +34 (93) 40167 94. E-mail; jasmina.berbegal@upc.edu

${ }^{5}$ Family Business Research Center. Universidad de las Américas Puebla. Ex hacienda Sta. Catarina Mártir, Cholula, Puebla 728I0, México.

Tel. +52 (222) 22924 53. E-mail: jorgea.duran@udlap.mx
} 


\section{Introduction}

Form many decades, research in business ethics and entrepreneurship has gained legitimacy in the academic and scientific community. The interest in research that links these two fields of knowledge arises because the business context often faces the entrepreneur with ethical dilemmas whose solution directly affects the firm performance (Bucar and Hisrich, 200I). This acquires a special assessment when the entrepreneur, who constantly seeks entrepreneurial opportunities in a changing competitive environment, must translate these into improved firm performance (Hitt et al. 200I).

Previous studies show that founder-managers of small businesses differ from others in recognizing the moral nature of a situation (Vyakarnam et al. 1997; Quin, 1997; Teal and Carroll, 1999; Spence, 1999), or, said in other terms, in Moral Awareness (MA) (Reynolds, 2006). Moreover, Butterfield, Trevino and Weaver (2000) observed that in the absence of a MA, it is likely that the entrepreneur will not identify the moral implications of their decisions and behavior, which affects the future viability of the business or, in terms of Lumpkin and Dess (1996), in their Entrepreneurial Orientation (EO).

Previous works in the entrepreneurship field confirm a positive relationship between the EO of the firm and its performance, especially in hostile and technologically sophisticated environments (Walter, Auer and Ritter, 2006). The commercialization of technology by the New Technology Based Firms (NTBFs), usually challenge markets and standards, while trying to get new customers (Morris et al. 2002). In addition, NTBFs are often monitored by rival companies that may be able to imitate their products or services quickly on a major scale, or simply can be acquired by other larger companies.

In a business context where competitiveness is governed by the technological innovation, the Technology Founders-Managers (TFM) regularly face moral issues when they have to choose between pursuing their own interests without harming others, or compromise norms of behavior (Sarasvathy, 2002). Nevertheless, and in spite of the importance of this phenomenon, the study of business ethics in the particular field of NTBFs is virtually nonexistent. This research focuses precisely on this lack of knowledge by exploring the factors that influences the MA of the TFM in the relationship that exists between EO and the performance controls of their NTBF.
There are three reasons for this research. First, without acknowledging a moral component in a situation, there cannot be a consideration of this component in decision making and behavior (VanSandt, Shepard and Zappe, 2006). Second, MA is a facet of the moral behavior and the literature on this subject is scarce, especially in the field of TFM (Harris, Sapienza and Bowie, 2009; Spence and Rutherford, 2003). Third, no research has related the MA's concept to the EO and the performance of NTBF. In the next section, the theoretical research framework as well as the research hypotheses is presented. Later, the proposed methodology of the study is developed and the analytical techniques used are demonstrated. The next section presents the main results, for further discussion and conclusion. Finally are presented the limitations, future research streams and practical implications are discussed.

\section{Literature review}

\section{Moral awareness and technology founder-manager}

There are studies that attempt to model the process of decision making and people's moral behavior (Rest, 1994; Trevino, 1986; Jones, 1991). According to the proposal of these models, the MA is the first step, and occurs when a person is able to recognize the effect his decisions or actions can have, affecting the interests, welfare or personal expectations of others (Butterfield, Trevino and Weaver, 2000). Some authors define the MA simply as the ability a person has in admitting that a situation has a moral content and legitimately it can be considered from this approach (Lowry, 2003; Reynolds, 2006; Jordan, 2009). Given this proposal, Reynolds (2006) argues that the MA is stimulated in presence of two situations: the damage and the violation of norms of behavior. For Butterfield, Trevino and Weaver (2000), not only the presence of damage is important, but the magnitude of its consequences. Theoretically, if a person fails to identify the moral content of a situation, then he will be unable to include it in the process of decision making and behavior (Jones, 199I).

In regard to the particular area of the entrepreneur, the theoretical models of Solymossy and Masters (2002), Morris et al. (2002) and Hannafey (2003), allow identifying that there are several dimensions that influence the MA and consequently they are reflected in the decision and behavior of the entrepreneur. The research shows 
that the small businesses founders-managers are so diverse in their ethical values, often reflected in the cognitive heterogeneity referenced by Baron (2004), when identifying the problems they face (Vyakarnam et al. 1997; Vittel, Dickerson and Festervant, 2000). Some of these cognitive differences are due to the influence of the socio-cultural (Sommer, Welsh and Gubman, 2000; Bryant, 2009), demographic (Dawson, Breen and Satyen, 2002) or organizational factors (VanSand, Shepard and Zappe, 2006).

When the technologic variable was analyzed, the figure of the TFM appears. This is a person with wide professional experience and a formal high-level education, who creates and directs the NTBF (Marvel and Lumpkin, 2007). During the founding years of the firm, the TFM typically dominates the decision making process affecting the performance of the company on the market. For this reason the ethical standards of the TFM have a dominant effect in the firm. Consequently the TFM are not exempt from committing errors (Morris et al. 2002). Trevino and Youngblood (1990) believe that the formative structure of a new company is in the founder-manager himself.

\section{Entrepreneurial orientation and performance}

Although literature in the field of entrepreneurship remains unclear, several authors consider entrepreneurship as a phenomenon at firm level (Barringer and Bluedorn, 1999, Covin and Slevin, 1991, Stevenson and Jarrillo, 1990). Moreover, it is accepted that the different manifestations of entrepreneurship are based on innovations that lead to changes in resource development and the creation of new capabilities to pursue opportunities (Stopford and BadenFuller, 1994). The behavior of a company can be classified along a continuum that goes from highly conservative to highly entrepreneurial and the position of a company in this continuum describes their EO (Lumpkin and Dess, 1996).

Generally, the EO refers to the trends, processes and behaviors that lead a firm to enter new or established markets with new or existing products (Lumpkin and Dess, 1996). Based on various models of firm-level entrepreneurship (Covin and Slevin, 1991, Miller 1983, Miller and Friesen, 1982), Lumpkin and Dess (1996) developed five features that characterize the EO of a firm: autonomy, risk taking, innovativeness, proactiveness and competitive aggressiveness. Autonomy is the degree to which organizational factors (people and equipment) act independently, making decisions, and pursuing opportunities. Risk taking is the tendency of the firm to support projects in which profits are uncertain. Innovativeness indicates the trend of the firm to support new ideas and foster creative processes that are intended to develop new products and services. Proactiveness is about taking initiative and pursuing new business opportunities in emerging markets. The competitive aggressiveness is to challenge the competition, in order to enter a new market or improve their competitive position.

The relationship between EO and performance has been an object of study for many decades and it has been demonstrated that firms that adopt an EO, perform better than companies that take a conservative orientation (Rauch et al. 2009). The NTBFs are vulnerable when taking a conservative approach due to limited capital, debt and market competitiveness, which subjects them to significant fluctuations in demand, aggressive competition practices and lack of support from suppliers and distributors (Autio, 1997). In addition it is necessary to uncover new opportunities and make adjustments to technology strategy to remain competitive in the market place (Montiel-Campos et al. 2009).

The EO can create conditions that stimulate ethical commitments, by assuming the dominant role using the values of the founder-manager to form a strong entrepreneurial culture, including collective behavior in the firm through its EO (Hofstede, 1985). Based on these arguments, this exploratory study examines the moderating effect of the MA of the TFM in the relationship to EO and performance of the NTBF. Formally stated, this study establishes the following hypothesis:

The relationship between the entrepreneurial orientation of a new technology based firm and its performance is moderated by the moral awareness of technology founder-manager. 


\section{Method}

\section{Sample and data collection}

The sample for this study consisted of technology based firms that started commercial operations between two and four years (2006 and 2008) prior to data collection by the end of 2010 (Littunen, Storhammar and Nenonen, 1998). Every firm should have a maximum of 50 employees as a criterion to consider the business as a small business according to the Secretariat of Economy in Mexico. Finally, the new firm should be identified with a technical field. Based on these criteria and with the support of the 20 high-tech business incubators, members of the National Business Incubation Association in Mexico, 304 NTBF were identified.

Since the purpose of this study was to explore the relationship between variables, the survey method was used for the data collection. To strengthen the external validity of the study, questionnaires were reviewed for any problem or irregularity. The questionnaires were pre-tested with TFM but they were not part of the final sample. Any doubts and lack of clarity were corrected in newer versions of the questionnaire. Finally, the definitive questionnaires were sent during the months of July to October 2010.

Contact information of the 304 TFM was obtained with the support of the 20 high-tech business incubators, to whom the questionnaire was sent electronically with a letter explaining the purpose of the study. Two weeks after the first letter was sent a follow-up letter thanking those who had already answered the questionnaire and a reminder to those that had not responded was sent. Four weeks after the first letter was sent, a reminder was sent, including a web address to give the respondents an opportunity to answer it online. Finally, 126 questionnaires were answered and used in the analysis. With reference to the variables used in the study, no significant differences were found among respondent at the beginning or end (Armstrong and Overton, 1977) or among those who responded electronically or by Internet (Dillman, 2000). The 126 companies used in this study can be subdivided into three groups: technology services (5I\%), consulting (21\% technology) and manufacturing technology (28\%). Companies have their own technological skills in different fields of technology, including automotive and aviation (I5\%), biotechnology (7\%), construction (9\%), chemicals and pharmaceuticals (7\%), computers (18\%) telecommunications (6\%), services (12\%), materials technology (8\%), energy and environmental technologies (6\%), and others. The average time the companies had been in business was 2.8 years and the average number of employees was 14.

\section{Measuring of constructs Independent variables}

This study used the EO measurement, identified as the Miller / Covin and Slevin scale (Brown, Davidsson and Wiklund, 200I). This scale contains constructs that measure the tendency of a firm towards innovativeness, risk taking, proactiveness, competitive aggressiveness and autonomy. Rauch et al. (2009) suggest that this scale and its derivatives represent a useful and valid means for measuring business decisions and actions at the organizational level. In total, 14 items were generated to measure the scale of the EO, which were presented to the TFM for their evaluation. A seven-point Likert scale was used to assess constructs to measure the trend of the firm towards EO. The average of the 14 items assessed the intensity of the $\mathrm{EO}$, therefore, the greater the average was, the more entrepreneurial strategic posture the firm had. The alpha coefficient of the scale was 0.83 .

In the data analysis, a confirmatory factorial analysis was performed (Jöreskog and Sörbom, 1996) to estimate the dimension of the model. Initial results suggest that it was not necessary to remove any item from the scale to improve the model fit. The fit of the model was evaluated using $\chi 2 / d f$, Goodness-of-Fit Index (GFI) (Jöreskog and Sörbom, 1996), and the Comparative Fit Index (CFI) (Bentler, 1992). The threshold for $\chi 2 / d f$ should be less than 3.0 or less than 2.0 in a more restrictive sense (Premkumar and King, 1994). The values of GFI and CFI should be above 0.90 (Jöreskog and Sörbom, 1996). The measurement of the model resulted in a good fit: $\chi 2 / \mathrm{df}$ $=2.33, \mathrm{GFI}=.923, \mathrm{CFI}=0.935$. All factor loading are in acceptable ranges and significant at $p=0.00 \mathrm{I}$, ranging from $0.5 \mathrm{I}$ to $0.8 \mathrm{I}$, indicating convergent validity (Anderson and Gerbin, 1988). The average variance obtained for the measurement of the EO was 0.52 , which is slightly above the threshold suggested by Bagozzi and Yi (1988). 
The method for measuring MA consisted of asking the TFM to identify among two to four problems, that in their opinion had important implications for decision making and courses of action, according to the scenario depicted in the "Hitting the glass ceiling " (Harris, Pritchard and Rabins, 1995) case. Although the process of perception occurs mentally, the fact that the person reporting the problem indicates conclusively that he has recognized it, is evidence of his awareness of the problem (VanSandt, Shepard and Zappe, 2006). Although the opposite, i.e. that does not identify a problem, is not conclusive evidence to suppose that the person failed to recognize the problem, but just might find it irrelevant. The case used was previously tested on three TFM that were not part of the final sample, in order to verify his/her moral ambiguity and other relevant attributes. The moral ambiguity became operative by the fact of giving equivalent magnitude to the moral and strategic problems (Sparks and Hunt, 1998).

The MA was assessed using a qualitative approach similar to those used in previous studies (Butterfield, Trevino and Weaver, 2000; VanSandt, Shepard and Zappe, 2006). After describing the problems that each TFM found relevant to decision making outlined in the case, they were asked to evaluate the importance of each problem on a scale of I to 7. This method was used for two reasons. First, the definition of MA refers to the degree to which a person recognizes the aspects of a situation and a Likert scale is best suited to this. Second, the scale provides the measurement of a variance, which allows representing in a more accurate way the complexity of the MA concept, as described by Blum (1994).

The valuations that were given to the problems identified by each of the TFM, required further classification by two experts in business ethics, who were not part of the team that conducted this research and therefore, were not familiar with the hypothesis that was being pursued. The purpose was to avoid possible bias that could result if the authors were those making the classification, which consisted of placing a zero (indicating that the problem identified did not have a moral component) or one (indicating that the problem identified did have a moral component). An average assessment of moral issues was obtained for each TFM who were identified with one. The internal reliability was relatively high, with a value of 0.92 using the Cronbach coefficient.

\section{Dependent variable}

The validity of evaluating the performance of the firm through perceptual measurements by the lack of having hard data has been well received according to several authors (Brush and Vanderwerf, 1992; Cooper, 1993, Chandler and Hanks 1993, Wiklund and Shepherd, 2003). When evaluating the performance of a firm compared to its principal competitors, it offers a higher level of reliability and validity. Performance measurement was the average of six indicators related to the internal efficiency and sales performance, which have been used in previous studies examining the relationship between the firm's strategic posture and its performance (Li and AtuaheneGima, 200I, Walter, Auer and Ritter, 2006; Lichtenthaler, 2009, Parida et al. 2010). The TFM were asked to indicate on a seven-point Likert scale, the performance of their firm compared to their principal competitors over the past two years. The alpha coefficient for the scale of performance of the firm was 0.79 . The model proved a good fit: $\chi 2 / \mathrm{df}=2.52, \mathrm{GFI}=.9 \mathrm{I}, \mathrm{CFI}=0.924$ and the load of each indicator were significant at $p=0.001$ with a range between $0.6 \mathrm{I}$ and 0.92 .

\section{Control variables}

The literature demonstrates that different environmental conditions, such as hostility, dynamism and technological sophistication influence the EO-firm performance relationship (Covin and Covin, 1990, Lumpkin and Dess, 200I; Wiklund and Shepherd, 2003, Parida et al. 2010), therefore, these factors were controlled during analysis. Hostile environments are characterized according to Khandwalla (1977, p. 335) as "risky, stressful and dominant." These environments are typical in precarious industries, intense competition and the limited availability of opportunities (Covin and Slevin, 1989). The hostility was measured by using the average of the three items in a seven-point semantic differential scale developed by Covin and Covin (1990). The higher the average of the three items, the more hostile the environment in which the firm operates. The alpha coefficient was 0.79 .

Dynamic environments are affected by unpredictable changes in the environment of the firm and uncertainty, which reduces the ability of managers to predict future events that may impact the organization (Khandwalla, 1977). Environmental dynamism was measured by averaging the three items that make up the seven-point 
semantic differential scale of Miller and Friesen (1982). The higher the average of the three items, the greater the dynamism of the environment in which the firm operates. The alpha coefficient was 0.82 .

According to Khandwalla (1977) the environment is classified as technologically sophisticated when the products and processes used in industry involve the use of sophisticated and complex technology operations as well as extensive work on research and development. The technological sophistication of the environment was evaluated by averaging two items in the seven-point semantic differential scale developed by Covin and Covin (1990). The higher the average of the two items, the more technologically sophisticated the environment in which the firm operates. The alpha coefficient was 0.84

\section{Results}

Averages, standard deviations and Pearson correlations between firm performance, EO, MA and the control variables are presented in Table I. The correlation between $E O$ and MA was positive and statistically significant. In addition, a hostile, dynamic and technologically sophisticated environment is associated with a higher EO, which is confirmed by previous studies (Covin and Slevin, 1989; Lumpkin and Dess, 1996; Wiklund and Shepherd, 2003). In regard to the performance of the firm, both the EO and the MA showed a positive and significant relationship.

To test the hypothesis a moderated hierarchical regression analysis was used (Cohen and Cohen, 1983), with a process centered on the mean of the independent and control variables in order to minimize multicollinearity (Aiken and West, 1991). The result of Variance Inflations Factors was below 3 , suggesting that multicollinearity is not a problem in the analysis. Table 2 provides the regression results for different models. Model I shows only the control variables, Model 2 adds the EO effect, and model 3 adds the MA direct effect. The results of the model 2 are consistent with previous studies, showing a positive effect of EO in the performance of the firm $(\beta=0.377, p<0.01)$, and EO variable explains the additional variance $(\triangle R 2=0.091, P$ $<0.0 \mathrm{I})$. In Model 3, adding the MA variable increases the variance explained $(\triangle R 2=0.183, p<0.01)$, suggesting that this factor also affects the performance of the firm.

\begin{tabular}{|c|c|c|c|c|c|c|c|c|}
\hline Variable & Mean & SD & 1 & 2 & 3 & 4 & 5 & 6 \\
\hline 1 Firm performance & 4.31 & 0.78 & 1.00 & & & & & \\
\hline 2 Entrepreneurial orientation & 3.96 & 0.74 & $0.38^{* * *}$ & 1.00 & & & & \\
\hline 3 M oral awareness & 3.66 & 0.77 & $0.46^{* *}$ & $0.49^{* *}$ & 1.00 & & & \\
\hline 4 Environmental hostility & 3.41 & 1.13 & $0.18^{* *}$ & $0.32^{* * *}$ & $0.12^{* *}$ & 1.00 & & \\
\hline 5 Environmental dynamism & 4.01 & 0.92 & $0.09^{* *}$ & $0.19^{* * *}$ & $0.15^{* *}$ & $0.09^{* * *}$ & 1.00 & \\
\hline $\begin{array}{l}6 \text { Environmental technological } \\
\text { sophistication }\end{array}$ & 3.12 & 0.88 & $0.10^{*}$ & $0.17^{* * *}$ & $0.05^{* *}$ & $0.06^{*}$ & $0.07^{* * *}$ & 1.00 \\
\hline
\end{tabular}

Table I. Descriptive statistics and correlations./ $\mathrm{N}=126 * \mathrm{p}<0.10 ; * * \mathrm{p}<0.05 ; * * *^{*}<0.0 \mathrm{I}$ 


\begin{tabular}{|lcccc|}
\hline Independent variable & Modd 1 & Model 2 & Modd 3 & Modd 4 \\
\hline Constant & $3.314^{* * *}$ & $3.201^{* * *}$ & $3.217^{* * *}$ & $3.411^{* * *}$ \\
Control variables: & & & & \\
$\quad$ Environmental hostility & $0.095^{* *}$ & $0.086^{*}$ & $0.101^{*}$ & $0.088^{*}$ \\
$\quad$ Environmental dynamism & $0.310^{*}$ & $0.701^{* *}$ & $0.198^{* *}$ & $0.963^{*}$ \\
$\quad$ Environmental technological sophistication & $0.184^{* *}$ & $0.177^{* *}$ & $0.901^{*}$ & $0.088^{* *}$ \\
M ain effects: & & $0.377^{* * *}$ & $0.183^{* * *}$ & $0.211^{* * *}$ \\
$\quad$ Entrepreneurial orientation & & & $0.358^{* * *}$ & $0.291^{* * *}$ \\
$\quad$ M oral awareness & & & & $0.313^{* * *}$ \\
Interaction effect: & & & & \\
$\quad$ H: Entrepreneurial orientation x moral & & & & \\
$\quad$ awareness & $2.660^{* * *}$ & $5.644 * * *$ & $0.881^{* * *}$ & $6.355^{* * *}$ \\
F $\quad 0.088$ & 0.169 & 0.322 & 0.371 \\
R-square & & $0.091^{* * *}$ & $0.183^{* * *}$ & $0.113^{* * *}$ \\
\hline R-square & & & \\
\hline
\end{tabular}

Table 2. Regression results. $*_{\mathrm{p}}<0.10 ;{ }^{*} \mathrm{p}<0.05 ; * * *_{\mathrm{p}}<0.0 \mathrm{I}$

The hypothesis in this study predicts a moderating effect of MA on the relationship between EO and firm performance. To test this hypothesis, the interaction effect between EO and MA was added. Model 4 reveals a positive and significant interaction effect between $\mathrm{EO}$ and MA on the performance of the firm $(\beta=0.355, p<0.01)$, which corroborates the hypothesis of the investigation. To understand the nature of the interaction, the EO effects on firm performance were plotted, for both, high and low levels of MA (Aiken and West, 1991), as shown in Figure I. The graph suggests that when MA is low, the relationship between EO and performance is positive; when the MA is high, the EO has practically no connection with the performance of the firm.

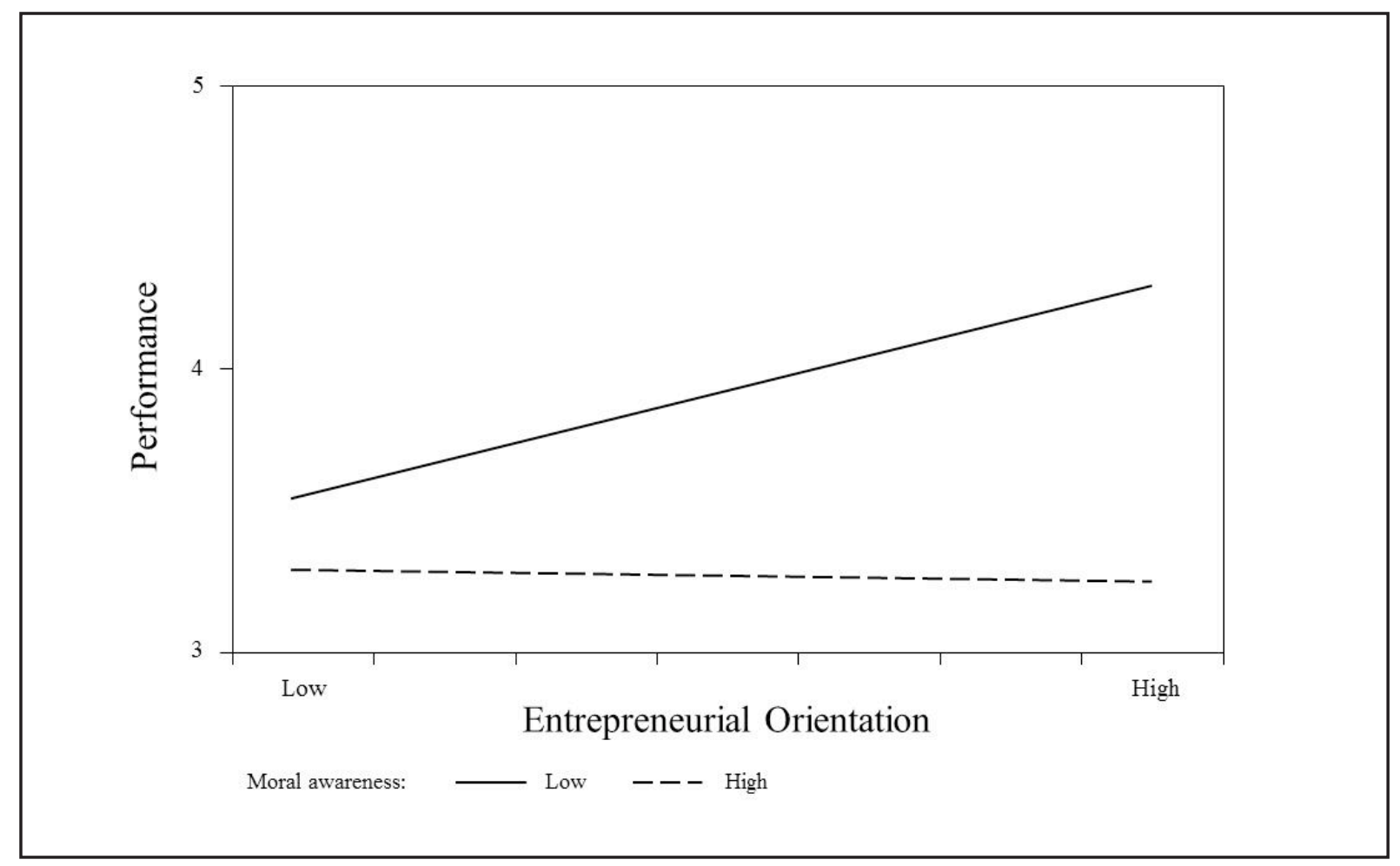

Figure I. Moderating effect of moral awareness on the entrepreneurial orientation-performance relationship 


\section{Discussion and conclusions}

The result of this work leads us to consider that the ability that a NTBF has to transform their EO in a good performance depends on the MA of the entrepreneur. In this sense, empirical evidence shows that the MA increases or decreases the relationship between EO and firm performance. This result also contributes to academic debate on internal contingent factors that promote EO (Covin, Green and Slevin, 2006; Wiklund and Shepherd, 2003). The effective implementation of EO depends not only on the strategic decisions made by the TFM, but also on the nature and consequences of those decisions, a situation that has been mentioned in previous studies (Lyon, Lumpkin and Dess, 2000). The results of this study also support the general idea that the EO-performance relationship depends on the context in which this relationship occurs (Walter, Auer and Ritter, 2006). This is evidenced by the influence that the dynamism control and technological sophistication variables have on the environment in the EO-performance relationship, which has also been demonstrated in previous research (Parida et al. 2010, Wiklund and Shepherd, 2003).

The results show that there is always a positive relationship between $\mathrm{EO}$ and the performance of the firm, although this relationship shows nuances when the nature of the MA is considered. The relationship is strong and positive only with low levels of MA. This can lead to various interpretations, amongst which could be, a consideration that the TFM sacrifices friendly competition in exchange for achieving a better competitive position in the market, or, the competitive environment generated by the technology makes the TFM not able to fully identify the moral content of the situations under which decisions must be made (Jones, 1991). In this sense, the NTBFs can use the EO as an effective means to achieve competitive advantages. The moderating effect of MA on the EO-performance relationship can help the firm stay in business, attract new customers and enhance its reputation as a competent provider of technology products and services. Similarly, the EO could contribute to the relational capital of the firm, which can be viewed as an investment in a market position (Kale, Singh and Perlmutter, 2000). Due to the small size of the firm, weak market recognition, the lack of a reputation and the innovation of its products, the NTBFs also depend on the development of good labor relations while aggressively entering new markets and try to identify the needs of their clients who can provide their technologies.
The results also support the general idea that the entrepreneurial posture of the NTBFs should be based on capabilities that promote the search for opportunities and accelerate the introduction of new products and services (Eisenhardt and Martin, 2000). This is why the NTBFs should recognize that the EO alone is not enough to compete in today's markets, and serves as a starting point that may help to better leverage their capabilities and impact on the performance of the firm. In addition, the entrepreneurial posture by itself does not create value and should not be seen as the only force for prosperity and sustainable growth of the NTBFs.

\section{Limitations, future research and practical implications}

Although the results of this study are illustrative in different ways, the theoretical implications for future studies should be interpreted in the light of the constraints. First, there is no reason to believe that the hypothesis of this work can be applied under other circumstances, such as companies that are not new or technology-based, so future research could examine the external validity of results in other contexts. Second, future work could make use of another procedure to help recognize and appreciate the importance of moral issues. In this sense, the MABI (Moral Awareness in Business Instrument) may be useful (Sparks and Hunt, 1998). Third, the study used an approach of unique and key informants; such is the case of the TFM, who are assumed to be well informed about their own organization. However, debate continues about the use of multiple responses from an organization to ensure the validity of the results. Fourth, the crosssectional nature of the data requires caution when reaching causal inferences, because the relationships being analyzed may be susceptible to reverse causality. To avoid this possibility, future work should identify internal and external aspects that detonate the MA when studying the EO and performance over time. Fifth, future research could explore whether the interaction effects studied in this work behave differently in different areas of the firm, such as financial, operational or marketing. Sixth, the results are supported by the NTBFs in Mexico. It is important to consider that cultural factors may interfere with the results, especially when within the dominant 
culture or customs there are businesses practices that are positive or negative (Hofstede, 200I). Finally, the performance of the firm is measured on the basis of subjective data. This data have shown similar results to the objective data (Walter, Auer and Ritter, 2006). The addition of objective data in future studies could increase the validity of the results.

The results of this work, in addition to highlighting the importance of MA to achieve entrepreneurial aspirations, also show directive implications. When the firm is preparing to pursue an opportunity, the TFM should not only focus on the nature of the opportunity and external environment conditions, but must also consider the implications inside and outside the firm in its decisionmaking, in order to avoid negative consequences. The lack of a MA can increase the variety of strategic decisions for the firm; however, this depends on the cognitive orientation of TFM or its dominant logic (Bettis and Prahalad, 1995).

In conclusion, it is expected that this work draws more attention to the factors that lead a NTBF to have a good performance through an EO. This paper provides a first attempt to better understand the influence of the MA in this process, in a way that entrepreneurial posture becomes a stronger competitive position.

\section{References}

AIKEN, L.S.; West, S.G. (1991). Multiple regression: Testing and interpreting interactions. Sage: Newbury Park, CA.

ANDERSON, J.C.; Gerbing, D.W. (1988). Structural equation modeling in practice: A review and recommended two-step approach. Psychlogical Bulletin, 103(3), 4II-423.

ARMSTRONG, J.S.; Overton, T.S. (1977). Estimating nonresponse bias in mail surveys. Journal of Marketing Research, 14(3), 396-402.

AUTIO, E. (1997). New technology-based firms in innovation networks symplectic and generative impacts. Research Policy, 26(3), 263-28I.

BAGOZZI, R.P.; Yi, Y. (1988). On the evaluation of structural equation models. Journal of the Academy of Marketing Science, 16(I), 74-94.
BARON, R.A. (2004). The cognitive perspective: a valuable tool for answering entrepreneurship's basic "Why" Questions. Journal of Business Venturing, 19(2), 221-239.

BARRINGER, B.R.; Bluedorn, A.C. (1999). The relationship between corporate entrepreneurship and strategic management. Strategic Management Journal, 20(5), $421-444$.

BENTLER, P.M. (1992). EQS structural equations program manual. BMDP Statistical Software: CA

BETTIS, R.A.; Prahalad, C.K. (1995). The dominant logic: Retrospective and extension. Strategic Management Journal, 16(I), 5-14.

BLUM, L.A. (1994). Moral Perception and Particularity. Cambridge University Press, Cambridge.

BROWN, T.E.; Davidsson, P.; Wiklund, J. (200I). An operationalization of Stevenson's conceptualization of entrepreneurship as opportunity-based firm behavior. Strategic Management Journal, 22(10), 953-968.

BRUSH, C.G.; Vanderwerf, P.A. (1992). A comparison of methods and sources for obtaining estimates of new venture performance. Journal of Business Venturing, 7(2), 157-170.

BRYAN, P. (2009). Self-regulation and moral awareness among entrepreneurs. Journal of Business Venturing, 24(5): 505-518.

BUCAR, B.; Hisrich, R.D. (200I). Ethics of Business Managers vs. Entrepreneurs. Journal of Developmental Entrepreneurship, 6(I), 59-82.

BUTTERFIELD, K.; Trevino, L.K.; Weaver, G. (2000). Moral Awareness in Business Organizations: Influences of Issue-Related and Social Context Factors. Human Relations, 53(7), 98I-10I8.

CHANDLER, G.N.; Hanks, S.H. (1993). Measuring the performance of emerging business: A validation study. Journal of Business Venturing, 8(5), 39I-408.

COOPER, A.C. (1993). Challenges in predicting new firm performance. Journal of Business Venturing, 8(3), 24I-254. 
COHEN, J.; Cohen, P. (1983). Applied multiple regression/ correlation analysis for the behavioral sciences. Erlbaum, Hillsdale, NJ.

COVIN, J.G.; Slevin, D.P. (1989). Strategic management of small firms in hostile and benign environments. Strategic Management Journal, I0(I):75-87.

COVIN, J.G.; Covin, T.J. (1990). Competitive aggressiveness, environmental context, and small firm performance. Entrepreneurship Theory and Practice, 14(4), 35-50.

COVIN, J.G.; Slevin, D.P. (1990). New venture strategic posture, structure, and performance: an industry life cycle analysis. Journal of Business Venturing, 5(2), 123-135.

COVIN, J.G.; Slevin, D.P. (199I). A conceptual model of entrepreneurship as firm behavior. Entrepreneurship Theory and Practice, 16(I), 7-25.

COVIN, J.G.; Green, K.M.; Slevin, D.P. (2006). Strategic process effects on the entrepreneurial orientation-sales growth rate relationship. Entrepreneurship Theory and Practice, 30(I), 57-8I.

DAWSON, S.; Breen, J.; Satyen, L. (2002). The ethical outlook of micro business operators. Journal of Small Business Management, 40(4), 302-313.

DILLMAN, D.A. (2000). Mail and Internet surveys: The tailored design method. New York: John Wiley \& Sons.

EISENHARDT, K.; Martin, J.A. (2000). Dynamic capabilities: what are they? Strategic Management Journal, $21(10 / I I), 1105-112 I$.

HANNAFEY, F.T. (2003). Entrepreneurship and ethics: a literature review. Journal of Business Ethics, 46(2), 99-100.

HARRIS, C.E.; Pritchard, M.S.; Rabins, M.J. (1995). Engineering Ethics: Concepts and cases. International Thomson Publishing. Belmont, CA.

HARRIS, J.D.; Sapienza, H.J.; Bowie, N.E. (2009). Ethics and entrepreneurship. Journal of Business Venturing, 24(5), 407-418.
HITT, M.; Ireland, R.; Camp, S.; Sexton, D. (200I). Introduction to the special issuestrategic entrepreneurship: entrepreneurial strategies for wealth creation. Strategic Management Journal, 22(6/7), 479-49l.

HOFSTEDE, G. (1985). The interaction between national and organizational value systems. Journal of Management Studies, 22(4), 347-357.

HOFSTEDE, G. (200I). Culture's consequences: comparing values, behaviors, institutions and organizations across nations. 2nd Ed. Sage, Thousand Oaks, CA.

JONES, T.M. (1991). Ethical Decision Making in Organizations: An Issue-Contingent Model. Academy of Management Review, 16(2), 366-395.

JORDAN, J. (2009). A social cognition framework for examining moral awareness in managers and academics. Journal of Business Ethics, 84(2), 237-258.

JÖRESKOG, K.G.; Sörbom, D. (1996). LISREL 8: The simplis command language. Chicago: Scientific Software International.

KALE, P.; Singh, H.; Perlmutter, H. (2000). Learning and protection of proprietary assets in strategic alliances: building relational capital. Strategic Management Journal, 2I(3), 2I7-237.

KHANDWALLA, P.N.(1977). The Design of Organizations. New York: Harcourt Brace Jovanovich.

LI, H.; Atuahene-Gima, K. (200I). Product innovation strategy and performance of new technology ventures in China. Academy of Management Journal, 44(6), II23-II34.

LICHTENTHALER, U. (2009). Absorptive capacity, environmental turbulence, and the complementarity of organizational learning process. Academy of Management Journal, 52(4), 822-846.

LITTUNEN, H.; Storhammar, E.; Nenonen, T. (1998). The survival of firms over the critical first 3 year and the local environment. Entrepreneurship and Regional Development, I0(3), 189-203. 
LOWRY, D. (2003). An investigation of student moral awareness and associated factors in two cohorts of an undergraduate business degree in a British university: Implications for business ethics curriculum design. Journal of Business Ethics, 48(I), 7-19.

LUMPKIN, G.T.; Dess, G.G. (1996). Clarifying the entrepreneurial orientation construct and linking it to performance. Academy of Management Review, 2I(I), I35-157.

LUMPKIN, G.T.; Dess, G.G. (200I). Linking two dimensions of entrepreneurial orientation to firm performance: the moderating role of environment and industry life cycle. Journal of Business Venturing, 16(5), 429-45I.

LYON, D.W.; Lumpkin, G.T.; Dess, G.G. (2000). Enhancing entrepreneurial orientation research: Operationalizing and measuring a key strategic decision making process. Journal of Management, 26(5), 1055-1085.

MARVEL, M.R.; Lumpkin, G.T. (2007). Technology entrepreneur's human capital and its effects on innovation radicalness. Entrepreneurship Theory and Practice, 3I(6), 807-828.

MILLER, D.; Friesen, P.H. (1982). Innovation in conservative and entrepreneurial firms. Two models of strategic momentum. Strategic Management Journal, 3(I), I-25.

MILLER, D. (1983). The correlates of entrepreneurship in three types of firms. Management Science, 29(7), 770-79I.

MORRIS, M.H.; Schindehutte, M.; Walton, J.; Allen, J. (2002). The ethical context of entrepreneurship: proposing and testing a developmental framework. Journal of Business Ethics, 40(4), 33I-36I.

MONTIEL-CAMPOS, H.; Del Palacio-Aguirre, I.; SoléParellada, F.; Nuño de la Parra, J.P. (2009). Technology Strategy and New Technology Based Firms. Journal of Technology Management and Innovation, 4(4), 42-52.

PARIDA, V.; Westerberg, M.; Ylinenpää, H.; Roininen, S. (2010). Exploring the effects of network configurations on entrepreneurial orientation and firm performance: an empirical study of new ventures and small firms. Annals of Innovation and Entrepreneurship, I(I), I-I3.
PREMKUMAR, G.; King, W.R. (1994). Organizational characteristics and information systems planning: An empirical study. Information Systems Research, 5(2), 75-109.

QUINN, J. (1997). Personal Ethics and Business Ethics: The Ethical Attitudes of Owner/Managers of Small Business. Journal of Business Ethics, 16(2), 119-127.

RAUCH, A.; Wiklund, J.; Lumpkin, G.T.; Frese, M. (2009). Entrepreneurial orientation and business performance: An assessment of past research and suggestions for the future. Entrepreneurship Theory and Practice, 33(3), 761-787.

REST, J.R. (1994). Background: theory and research. In J. R. Rest and D. Narvaez (eds). Moral development in the professions: Psychology and applied ethics. Lawrence Erlbaum Associates, New Jersey.

REYNOLDS, S. (2006). Moral awareness and ethical predispositions: investigating the role of individual differences in the recognition of moral issues. Journal of Applied Psychology, 91 (I), 233-243.

SARASVATHY, S.D. (2002). Entrepreneurship as economics with imagination. Ruffin Series in Business Ethics, 3, 95-112.

SOLYMOSSY, E.; Masters, J.K. (2002). Ethics through an entrepreneurial lens: theory and observation. Journal of Business Ethics, 38(3), 227-24I.

SOMMER, S.M.; Welsh, D.H.B.; Gubman, B.L. (2000). The ethical orientation of Russian entrepreneurs. Applied Psychology: An International Review, 49(4), 688-708.

SPARKS, J.R.; Hunt, S.D. (1998). Marketing researcher ethical sensitivity: conceptualization, measurement, and exploratory investigation. Journal of Marketing, 62(2), 92109.

SPENCE, L.J. (1999). Does Size Matter? The State of the Art in Small Business Ethics. Business Ethics: A European Review, 8(3), 163-174.

SPENCE, L.J.; Rutherford, R. (2003). Small business and empirical perspectives in business ethics: an editorial. Journal of Business Ethics, 47(I), I-5. 
STEVENSON, H.H.; Jarrillo, J.C. (1990). A paradigm of entrepreneurship: entrepreneurial management. Strategic Management Journal, II(4), 17-27.

STOPFORD, J.M.; Baden-Fuller, C.W.F. (1994). Creating corporate entrepreneurship. Strategic Management Journal, I5(7), 52I-536.

TEAL, E.J.; Carroll, A.B. (1999). Moral Reasoning Skills: Are Entrepreneurs Different?. Journal of Business Ethics, 19(3), 229-240.

TREVIÑO, L.K. (1986). Ethical Decision Making in Organizations: A Person-Situation Interactionist Model. Academy of Management Review, II(3), 60I-6I7.

TREVIÑO, L.K.; Youngblood, S.A. (1990). Bad apples in bad barrels: A causal analysis of ethical decision-making behavior. Journal of Apllied Psychology, 75(4), 378-386.

VANDSANDT, C.V.; Shepard, J.M.; Zappe, S.M. (2006). An examination of the relationship between ethical work climate and moral awareness. Journal of Business Ethics, 68(4), 409-432.

VITTEL, S.J.; Dickerson, E.B.; Festervant, T.A. (2000). Ethical problems, conflicts and beliefs of small business professionals. Journal of Business Ethics, 19(I), 15-24.

VYAKARNAM, S.; Bailey, A.; Myers, A.; Burnett, D. (1997). Towards an Understanding of Ethical Behaviour in Small Firms. Journal of Business Ethics, I6(I5), 1625-1636.

WALTER, A.; Auer, M.; Ritter, T. (2006). The impact of network capabilities and entrepreneurial orientation on university spin-off performance. Journal of Business Venturing, 2I(4), 54I-567.

WIKLUND, J.; Shepherd, D. (2003). Knowledgebased resources, entrepreneurial orientation, and the performance of small and medium sized business. Strategic Management Journal, 24(13), 1307-1314. 
J. Technol. Manag. Innov. 20II,Volume 6, Issue 4 